\title{
ФАКТОРЫ ПРОФЕССИОНАЛЬНОГО ВЫГОРАНИЯ СПЕЦИАЛИСТОВ СОЦИАЛЬНОЙ СФЕРЫ: РЕЗУЛЬТАТЬ РЕГРЕССИОННОГО АНАЛИЗА ДАННЫХ
}

\section{FACTORS OF PROFESSIONAL BURNOUT OF SOCIAL SPECIALISTS: RESULTS OF REGRESSION ANALYSIS OF DATA}

M. Zhigulina

Summary: The article presents the results of a study of the professional burnout of specialists in the social sphere, in particular, specialists in social protection. The features of the manifestation of burnout in these specialists are considered. With the help of regression analysis, the factors influencing the professional burnout of this group were identified. Such factors, in addition to organizational ones, may include factors reflecting the personal, communicative, special competence of the helping specialists.

Keywords: regression analysis, professional burnout, social specialists, personal competence, a fully functioning person.
Жигулина Марина Андреевна

Соискатель, ГОУ ВО Московской области «Московский государственный областной университет» (г. Мытищи)

Zhigulina_M_A@msph.ru

Аннотация: В статье представлены результаты исследования профессионального выгорания специалистов социальной сферы, в частности специалистов социальной защиты. Рассматриваются особенности проявления выгорания у данных специалистов. С помощью регрессионного анализа выявлены факторы, оказывающие влияние на профессиональное выгорание данной группы. К таким факторам, помимо организационных, возможно отнести факторы, отражающие личностную, коммуникативную, специальную компетентность помогающих специалистов.

Ключевые слова: регрессионный анализ, профессиональное выгорание, специалисты социальной сферы, личностная компетентность, полноценно функционирующий человек.

\section{Введение}

$\mathrm{O}$ дной из важнейших характеристик постиндустриального общества является все возрастающая интенсивность труда. Совершенствование технологий и их внедрение в производственную деятельность требует от специалистов высокого уровня компетентности, как профессиональной, так и личностной, умения гибко реагировать на возникающие задачи, быстро адаптироваться к изменяющимся условиям. Повышенные требования предъявляются и к качеству взаимодействия между поставщиками и потребителями услуг, что особенно важно в социальной сфере. В современных исследованиях отмечается, что работа в непосредственном контакте с людьми, требует от специалистов особой ответственности и эмоциональной включенности, что повышает вероятность возникновения профессионального стресса [7; 8]. По данным исследователей, профессиональному выгоранию подвержены свыше $30 \%$ специалистов социономических профессий (в том числе медицинский персонал, работники социальных служб, педагоги) [1]. Психологическое состояние персонала непосредственно влияет на эффективность и качество выполнения профессиональной деятельности [2].

Анализ литературы, посвященной феномену профессионального выгорания, показывает, что как зарубеж- ными, так и отечественными учеными, проведено значительное количество исследований, направленных на изучение различных аспектов профессионального выгорания, закономерностей его формирования, его проявления [7]. Однако, методам первичной и вторичной профилактики профессионально выгорания, оценки их эффективности уделено значительно меньше внимания $[4 ; 12]$.

\section{Материалы и методы}

Наше исследование посвящено изучению факторов, влияющих на предотвращение профессионального выгорания специалистов социальной сферы. Исследование проводилось на базе учреждений социальной защиты населения г. Москва. Общий объем выборки составил 338 человек (женщин -251, мужчин 87), в возрасте от 22 до 64 лет (средний возраст 44,9 \pm 10,7 лет). Для сбора эмпирического материала использовались тестовые методики [10; 11; 13], позволяющие выявить уровень личностной, коммуникативной и специальной компетентности специалистов с целью определения мишеней терапевтического воздействия:

- оценка уровня общительности (В.Ф. Ряховского), позволяющая оценить уровень общительности, коммуникабельности человека;

- диагностика уровня профессионального выгора- 
ния (Бойко В.В. 1996г.), позволяющая увидеть ведущие симптомы выгорания;

- “Поведение в конфликте” (К. Томас, адаптация Гришиной Н.В.);

- "Уровень субъективного контроля" (Е.Г. Ксенофонтовой (1999г.);

- Опросник SI-22 (E. Freire, 2009), определяющий уровень полноценного функционирования человека;

- Методика диагностики личностной зрелости (В.А. Руженков, В.В. Руженкова, И.С. Лукьянцева, 2016);

- Интегральная удовлетворенность трудом (Фетискин Н.П., Козлов В.В., Мануйлов Г.М.);

- Диагностика самоактуализации личности (САМОАЛ) (А.В. Лазукин, адаптация Н.Ф. Калина, 1998).

Обработка полученных данных проводилась с помощью пакета статистических программ SPSS 22.0.

Для определения силы влияния независимых переменных характеризующих компетентность специалистов, на зависимую переменную мы использовали множественный регрессионный анализ. В качестве зависимой переменной выступало профессиональное выгорание, а в качестве независимых переменных предполагаемые предикторы компетентности [6].

\section{Результаты исследования}

Результат пошагового регрессионного анализа представлен в таблице 1. Коэффициенты регрессии, представляющие силу и тип взаимосвязи независимых переменных по отношению к зависимой, представлены в таблице 2.

Полученные значения позволяют говорить о том, что предикторные переменные объясняют около 40\% дисперсии зависимой переменной (таблица 1). Значение критерия Дарбина-Уотсона (DW = 2,069) указывает на отсутствие автокорреляции, что является одним из подтверждений высокого качества модели [6].

Анализ коэффициентов регрессии ß (таблица 2) указывает на то, что наибольшее влияние на зависимую переменную, оказывает параметр «Удовлетворенность трудом» (УТ_49_УОБЩ), который отражает субъективное, эмоционально-оценочное отношение работника к трудовой деятельности. В социальной сфере, где эффективность, производительность труда не имеет количественного измерения, а выражается субъективными характеристиками (например, качеством контакта) удовлетворенность трудом не может оставаться без внимания [5]. Причем, чем выше уровень удовлетворенности трудом, тем ниже уровень профессионального выгорания.

Результат регрессионного анализа

Таблица 1.

Сводка для модели

\begin{tabular}{|r|l|r|l|l|l|}
\hline Модель & R & R-квадрат & $\begin{array}{l}\text { Скорректированньй } \\
\text { R-квадрат }\end{array}$ & $\begin{array}{l}\text { Стандартная } \\
\text { ошибка оценкн }\end{array}$ & $\begin{array}{l}\text { Дарбин- } \\
\text { Уотсон }\end{array}$ \\
\hline 1 &, $485^{\mathrm{a}}$ &, 235 &, 233 & 42,31190 & \\
2 &, $584^{\mathrm{b}}$ &, 341 &, 337 & 39,31389 & \\
3 &, $599^{\mathrm{c}}$ &, 359 &, 353 & 38,84719 & \\
4 &, $613^{\mathrm{d}}$ &, 375 &, 368 & 38,39947 & \\
5 &, $624^{\mathrm{e}}$ &, 389 &, 380 & 38,03035 & \\
6 &, $630^{\mathrm{f}}$ &, 397 &, 387 & 37,83046 & \\
7 &, $637^{\mathrm{g}}$ &, 406 &, 393 & 37,61859 & 2,069 \\
\hline
\end{tabular}

а. Предикторы: (константа), УТ_49_УОБЩ

b. Предикторы: (константа), УТ_49_УОБЩ, Ряховский

с. Предикторы: (константа), УТ_49_УОБЩ, Ряховский, Томас_21_ПР

d. Предикторы: (константа), УТ_49_УОБЩ, Ряховский, Томас_21_ПР, ПФЧ_39

е. Предикторы: (константа), УТ_49_УОБЩ, Ряховский, Томас_21_ПР, ПФЧ_39, Томас_19_кОМП

f. Предикторы: (константа), УТ_49_УОБЩ, Ряховский, Томас_21_ПР, ПФЧ_39, Томас_19_КОМП, УСК_22_ИО

g. Предикторы: (константа), УТ_49_УОБЩ, Ряховский, Томас_21_ПР, ПФЧ_39, Томас_19_КОМП, УСК_22_ИО, Томас_20_иЗБ

h. Зависимая переменная: Бойко_16_ОБЩ 
Следующая переменная, оказывающая влияние ( 0,293) «Ряховский». Следует отметить, что высокие показатели данной методики характеризуют недостаточную сформированность коммуникативной компетенции респондентов (им трудно «прислушиваться» к собеседнику, они склонны навязывать собственное мнение) [8].

Так же, данные показывают, что переменные, характеризующие поведение респондентов в конфликтной ситуации:

«Томас_21_ПР» (Приспособление) $ß=-0,188$;

«Томас_19_КОМП» (Компромисс) $ß=-0,156$;

«Томас_20_ИзБ» (Избегание) $ß=-0,099$, оказывают влияние на зависимую переменную и имеют обратное направление связи. Возможно, применительно к специалистам социальной сферы, это объясняется тем, что специалисты, с одной стороны, чутко относятся к получателям социальных услуг, принимая во внимание их специфику, проявляют гибкость во взаимодействии, что указывает на сформированность коммуникативной компетентности компетентности. С другой стороны, реалистично оценивают действительность, заботятся о собственном психологическом благополучии, сохраняя ресурсы в ситуациях, в которых они не могут повлиять на их исход.

Результаты анализа данных свидетельствуют о влиянии переменной «ПФЧ_39» (Полноценно функциони- рующий человек) $ß=0,140$. Чем выше показатели полноценного функционирования, тем ниже показатели выгорания. Критериями полноценно функционирующего человека, описанного К. Роджерсом, являются следующие характеристики:

- «открытость опыту» - способность принимать собственные переживания без защитных искажений не испытывая при этом чувства угрозы себе;

- «экзистенциальная жизнь» - способность полно проживать текущие моменты жизни без предубеждений и предвзятого мнения;

- «организмическое доверие» - способность принимать решения и выбирать поведение, основываясь на собственных внутренних ощущениях;

- «эмпирическая свобода»- способность проявлять гибкость и адаптивность, произвольную регуляцию, наличие внутреннего локуса контроля;

- «креативность»- способность проявлять творческое отношение к жизни [9].

Переменная «УСК_22_иО» (Уровень субъективного контроля, интернальность общая) $ß=-0,111$, которая охватывает все пункты опросника “Уровень субъективного контроля» и описывает человека уверенного в том, что он во многом сам влияет на собственную жизнь, проявляя активность и беря на себя ответственность за собственные выборы [3]. Переменная «УСК_22_ИО» также имеет обратную связь с зависимой переменной.

Коэффициенты регрессии

\begin{tabular}{|c|c|c|c|c|c|c|c|}
\hline \multirow[b]{2}{*}{ Модель } & \multicolumn{2}{|c|}{$\begin{array}{c}\text { Нестандартизованны } \\
\text { е коэффнцненты }\end{array}$} & \multirow{2}{*}{\begin{tabular}{|c|}
$\begin{array}{c}\text { Стандартизованн } \\
\text { ые коэффицненты }\end{array}$ \\
Бета
\end{tabular}} & \multirow{2}{*}{ T. } & \multirow[b]{2}{*}{$\begin{array}{c}\text { Значнмоо } \\
\text { ть }\end{array}$} & \multicolumn{2}{|c|}{\begin{tabular}{|c|} 
Статнстика \\
коллинеарноств
\end{tabular}} \\
\hline & B & $\begin{array}{l}\text { Стандартн } \\
\text { ая ошнбка }\end{array}$ & & & & Допуск & VIF \\
\hline 7(Константа) & 283,360 & 30,995 & & 9,142 &, 000 & & \\
\hline ут_49_уоБш & $-4,688$ & ,772 &,- 295 & $-6,073$ &, 000 & ,763 & 1,311 \\
\hline Ряховскнй & 3,286 &, 531 & ,293 & 6,191 &, 000 &, 803 & 1,245 \\
\hline Toмac_21_חР & $-3,840$ & 931 &,- 188 & $-4,124$ &, 000 &, 864 & 1,158 \\
\hline ПФप_39 &,- 776 & 272 &,- 140 & $-2,855$ &, 005 & ,746 & 1,341 \\
\hline $\begin{array}{l}\text { Toмac_19_KOM } \\
\Pi\end{array}$ & $-4,851$ & 1,476 &,- 156 & $-3,287$ &, 001 &, 801 & 1,249 \\
\hline УСК_22_ио &,- 995 & ,433 &,- 111 & $-2,300$ &, 022 &, 772 & 1,295 \\
\hline Томас_20_ИзБ & $-2,927$ & 1,345 &,- 099 & $-2,177$ &, 030 &, 871 & 1,148 \\
\hline
\end{tabular}

Таблица 2. 


\section{Зак^ючение}

Таким образом, полученные результаты, позволяют говорить о том, что переменные, характеризующие личностную компетентность (УТ_49_УОБЩ, ПФЧ_39, УСК_22_ИО), коммуникативную и специальную компетентность (Ряховский, Томас_21_ПР, Томас_19_КОМП, Томас_20_ИЗБ) оказывают влияние на зависимую пере- менную (Бойко_16_ОБЩ), отражающую уровень профессионального выгорания специалистов социальной сферы, в частности социальной защиты населения, указывая на области работы по предотвращению выгорания. Оказывая терапевтическое воздействие, повышающее личностную, коммуникативную, специальную компетентность специалистов, возможно снижать проявления профессионального выгорания и предотвращать его формирование.

\section{ЛИТЕРАТУРА}

1. ВцИОМ: национальный мониторинг здоровья россиян (электронный ресурс) https://wciom.ru/index.php?id=236\&uid=922 дата 0бращения 17.09.2020.

2. Долгова В.И., Гольева Г.Ю. Эмоциональная устойчивость личности: монография. - М.: Перо, 2014. - 196 с.

3. Жигулина М.А. 0 психологической поддержке специалистов социальной сферы / М.А. Жигулина // Международная конференция по консультативной психологи и психотерапии, посвященная памяти Ф.Е. Василюка: сборник материалов [электронное издание] / под ред. В.В. Архангельской, А.А. Голзицкой, Н.В. Кисельниковой, Е.А. Семеновой. - М.: ФБГНУ «Психологический институт РАО», 2018. - С. 85-89

4. Жигулина М.А., Кузовкин В.В. Методы предотвращения профессионального выгорания / М.А. Жигулина // Психология психических состояний: сб. ста-тей магистрантов, аспирантов и молодых ученых / Под ред. А.В. Чернова, М.Г. Юсупова. Казань: Изд-во Казан. ун-та, 2019. - Вып. 13. - С. 355-358.

5. Жуйкова М.А. Удовлетворенность трудом как объект социологического изучения // Вестник Удмуртского университета. Серия «Философия. Психология. Педагогика». 2014. 1. URL: https://cyberleninka.ru/article/n/udovletvorennost-trudom-kak-obekt-sotsiologicheskogo-izucheniya-1 (дата обращения: 11.02.2020).

6. Наследов, А.Д. Математические методы психологического исследования: Анализ и интерпретация данных. Учебное пособие.- СПб.: Речь, 2004.- 392 с.

7. Платонов Ю.П. Феномен эмоционального выгорания личности: структурно-функциональный анализ // Учёные записки Санкт-Петербургского государственного института психологии и социальной работы. 2018. Том 29. № 1. С. 7-13.

8. Проничева М.М., Булыгина В.Г., Московская М.С. Современные исследования синдрома эмоционального выгорания у специалистов профессий социальной сферы // Социальная и клиническая психиатрия, 2018.-N 4.-С. 100-105

9. Роджерс К. Клиентоцентрированный/человекоцентрированный подход в психотерапии. //Московский психотерапевт. журн. - 2002. № 1. С.54-69.

10. Руженков В.А., Руженкова В.В., \& Лукьянцева И.С. Методика диагностики личностной зрелости // Научные ведомости Белгородского государственного университета. Серия: Медицина. Фармация, 2016. № 26 (247). С. 65-70. URL: https://cyberleninka.ru/article/n/metodika-diagnostiki-lichnostnoy-zrelosti (дата обращения: 17.12.2017).

11. Фетискин Н.П., В.В. Козлов, Г.М. Мануйлов // Социально-психологическая диагностика развития личности и малых групп. - М.: Изд-во Института Психотерапии, 2002. - С. 297-303.

12. Ahola, K., Toppinen-Tanner, S., \& Seppänen, J. (2017). Interventions to alleviate burnout symptoms and to support return to work among employees with burnout: Systematic review and meta-analysis. Burnout Research, 4, 1-11. http://dx.doi.org/10.1016/j.burn.2017.02.001

13. Freire E., Elliott R., \& Cooper M. (2007). The Strathclyde Inventory: Validation of a person-centred outcome measure. Paper presented at the 13th Annual BACP Counselling and Psychotherapy Research Conference, York, UK.

( ) Жигулина Марина Андреевна (Zhigulina_M_A@msph.ru). 